\title{
Is Low Level of Serum Ionized Magnesium Responsible for Eclampsia?

\author{
R AKTHER ${ }^{\mathrm{a}}$, M RASHID
}

\begin{abstract}
Summary:
Objective: To determine the level of serum ionized magnesium in eclampsia patient before and 24 hours after giving the loading dose of magnesium sulfate and if low, to determine the relationship between levels of ionized magnesium in serum and occurrence of eclamptic convulsions.
\end{abstract}

Methods: Fifty eclampsia patients received a loading dose of $4 \mathrm{gm}$ of magnesium sulfate, which was diluted with 12 $\mathrm{ml}$ of distilled water and then was given intravenously over a period of 10-15 minutes and it was followed by $3 \mathrm{gm}$ of magnesium sulfate deep intramuscular injection in each buttock. Patient's venous blood samples were obtained before and 24hours after loading dose of magnesium sulfate and analyzed for ionized magnesium, sodium, potassium, and calcium level.

\section{Introduction:}

Eclampsia is one of the important cause of maternal and perinatal morbidity and mortality throughout the world. Though the cause of eclampsia is unknown but now a day's eclampsia is considered as a malnutrition related disease ${ }^{1}$. Eclampsia commonly seen in teenage pregnant woman who lives in slum area, devoid of both home care and antenatal care. In Bangladesh, eclampsia accounts five percent of total obstetric admission in our health facilities and sixteen percent of maternal death.$^{2}$

Malnutrition is common in our country. Pregnancy imposes a great stress on the nutritional reserves. There is depletion of essential nutrients like VitaminB complexes, Vitamin-A, Folic acid, Iron and Calcium. Intake of this essential nutrient in poor

a. Dr. Rabeya Akther, FCPS, Bangladesh Bank Medical Center, Dhaka, Bangladesh;

b. Prof. Maliha Rashid, FCPS, Dhaka Medical Collage Hospital, Dhaka, Bangladesh

Address of correspondence: Dr. Rabeya Akther, FCPS, (Obstetric \& Gynaecology), Assist Chief Medical Officer, Bangladesh Bank Medical Center, Motijheel, Dhaka, Bangladesh, Tel: 8313533 , 01817517100 (Mobile), Email: rabeyrakther@yahoo.com

Received: 15 March, 2008

Accepted: 2 June, 2009
Results: Level in eclampsia women is $0.47(0.15-1.04) \mathrm{m}$ $\mathrm{mol} / \mathrm{L}$ and $0.74(0.20-2.00) \mathrm{m} \mathrm{mol} / \mathrm{L}$ before and 24 hours after treatment with loading dose of magnesium sulfate, respectively. This change is significant. $(P$ value is $<$ 0.001). Change in ionized magnesium level associated with change in diastolic and systolic blood pressure, mean arterial pressure and albuminuria. This changes are also significant $(p<001)$.

Conclusions: The evidence indicated that low level of ionized magnesium in serum may be the cause of eclamptic convulsion.

Key word: Ionized magnesium, Eclampsia, magnesium sulfate.

(J Bangladesh Coll Phys Surg 2009; 27: 76-81)

income women is far below than recommended daily allowances. 3 Decreased protein intake causes decrease calcium absorption from the gut and stimulate parathyroid hormone secretion .Thereby enhance calcium reabsorption from bone and maintain calcium balance. ${ }^{4}$ There is progressive decline in magnesium consumption from 475-500 $\mathrm{mg} /$ day in 1900 - 1908 to $175-225 \mathrm{mg} /$ day in 19902002 due to widespread consumption of processed foods and decreased consumption of fresh foods ${ }^{5}$.Nuts and green leafy vegetables are good sources of magnesium. ${ }^{5}$

Eclampsia is primarily a convulsive state, despite extensive physiological, biochemical and anatomical changes that occur during pregnancy and may be local or systemic ${ }^{6}$, serum electrolytes and ionized $\mathrm{Ca}^{2+}$ level remain normal ${ }^{6-8}$ So present study has focused on ionized magnesium level. Magnesium is one of four cations that must be kept in balance in extra cellular fluid to regulate all body functions that require ATP. ${ }^{9,10}$

In women with eclampsia, magnesium deficiency is suspected. Because during normal pregnancy plasma volume increases $50 \%$, increased metabolic and endocrine activity of mother and fetus, estrogen and 
progesterone levels which increases as pregnancy advances ${ }^{6,7}$, elevates the body's demand for magnesium $^{11}$ and more and more magnesium are utilized and produce physiological hypomagnesaemia and symptoms of hypomagnesaemia. ${ }^{4,10-13}$ On the other hand, if pregnancy remain uncared, women have no ANC, decreased dietary supply of protein ${ }^{3}$, vitamins and minerals, preexisting protein energy malnutrition, low maternal age, .low income, low quality of life, these lead to severe micronutrient deficiency particularly magnesium deficiency that causes tissue hyperirritability and convulsion .4,10-13

Serum magnesium level is tightly regulated in a narrow range of approximately 0.7 to $1.0 \mathrm{mmol} / \mathrm{l}$ because only $1 \%$ of the total body content of magnesium is extra cellular. 9 When serum ionized magnesium level falls below $0.7 \mathrm{~m} \mathrm{~mol} / \mathrm{L}$ are indicative of magnesium deficiency. But patient remain asymptomatic ${ }^{9}$. Symptoms appear when level falls below $0.5 \mathrm{~m} \mathrm{~mol} / \mathrm{L}$. This level indicate depleted total body magnesium stores because magnesium reside in side the cell, total body magnesium deficit is often $200 \mathrm{~m} \mathrm{~mol}(4800 \mathrm{mg})$ by the time serum level falls to $<0.5 \mathrm{~m} \mathrm{~mol} / \mathrm{L} .9$ Magnesium is a natural calcium blocker ${ }^{5}$. Alteration of intra and extra cellular magnesium concentration may affect cell function through their effect on calcium handling. There is evidence that magnesium acts by opposing calcium dependent arterial vasoconstriction by antagonizing the increase in intracellular $\mathrm{Ca}^{+2}$ concentration caused by ischemia. ${ }^{14}$

Magnesium depletion causes impaired parathyroid hormone secretion and function 9, 14 and chronic magnesium deficiency causes damage to the cardio vascular, renal and neuromuscular tissue ${ }^{10}$. It enhance the contractility of several vascular beds in vitro, including coronary arteries, the mesenteric vasculature and umbilical vessels and may potentiate the contractile response to humoral agents such as nor adrenalin, prostaglandins and angiotensin II and leads to wide spread vasoconstriction 12,14. Vasoconstriction causes increased resistance to blood flow and accounts for the development of arterial hypertension. Vasoconstriction induced ischemia may be sufficient enough to lower the epileptiform activity in affected region of brain 5,15

\section{Methods:}

This study is designed to estimate level of serum ionized $\mathrm{Mg}^{+2}$ in eclampsia women before and 24 hours after giving the loading of magnesium sulfate and to determine the relationship between low level of ionized magnesium and occurrence of eclamptic convulsion. This is a prospective study carried out in Dhaka Medical College Hospital, Dhaka, Bangladesh during the period of July 2003 to September 2004. The patients were selected randomly. All patients with a clinical diagnosis of eclampsia, not received magnesium sulfate before admission, were eligible for the study irrespective of when or where fit had occurred, whether the baby was delivered or not. Follow up was done to the other ward, discharged from the hospital or until death (whichever came first).All patients received a loading dose of $4 \mathrm{gm}$ of magnesium sulfate, which was diluted with $12 \mathrm{ml}$ of distilled water and then was given intravenously over a period of 10-15 minutes and it was followed by 3 gm of magnesium sulfate deep intramuscular injection in each buttock. Patient was followed up at fifteen minutes interval, points noted during follow up were respiratory rate more than 16 per minute, urine output more than $25 \mathrm{ml}$ per hour and presence of knee jerk and thereafter follow up was done 4 hourly. This dose schedule has been found out to be effective for Bangladeshi women in a well designed study. ${ }^{2}$

Two venous blood samples were taken before and 24 hours after giving the loading dose of $\mathrm{MgSO}_{4}$. Two $\mathrm{ml}$. of venous blood was taken with a plastic syringe from the antecubital vein. Blood was transferred to a test tube containing heparin for determination of serum electrolytes particularly ionized magnesium. The investigation was done at Biomedical Research Group, Bangladesh Institute of Research and Rehabilitation in Diabetes Endocrine\& Metabolic Disorder. NOVA-8 was used as analyzer instrument. Reference range of Serum magnesium 0.7$1 \mathrm{mmol} / \mathrm{L}{ }^{11}$ Ethical clearance was obtained from BCPS Ethical Review Committee for the study. Informed consent was obtained from each patient for publication and presentation.

\section{Data Analysis}

All collected data were compiled and appropriate statistical analysis were done using computer based 
software (SPSS for windows, version 10.1). Results are expressed as median (Rang). For statistical comparison, non-parametric tests i.e. Wilcoxon Signed Ranks Test. Pearson's correlation were used. All tests were two sided, and statistical significance was inferred for $\mathrm{P}$ values less than 0.05 .

\section{Results:}

For the purpose of this study, fifty eclampsia patients have been studied. Median age of the participant women is $21(17-34)$ years. Forty eight percent of them are less than 20 years old, forty two percent belong to age group 21-30 years and only 10 percent belong to age group 3135 years. Seventy two percent of the patients are primi and remaining are $2^{\text {nd }}, 3^{\text {rd }}$ and $4^{\text {th }}$ gravid. Seventy two percent of the women have no ante natal care. Only 28 percent of the women have regular ante natal care. Sixty eight percent of the patient developed ante partum eclampsia and sixteen percent women developed intrapartum eclampsia. Only fourteen percent women developed eclampsia before 34 weeks of gestation, thirty percent of the women developed eclampsia between 34 37 weeks of gestation and forty percent of women developed eclampsia after 37 weeks of gestation. Sixteen percent women developed postpartum eclampsia and all are term pregnancy. Ninety percent of women have monthly income less than 3500/taka.They (husband) are day labors. (Table I).

\section{Table-I}

Demographic characteristics of the patients in the study

\begin{tabular}{lc} 
Variables & Frequency \\
\hline Age (mean) & $21(17-34) \mathrm{yrs}$ \\
Primi gravida & $72 \%$ \\
ANC- NO & $72 \%$ \\
Types of eclampsia: antepartum eclampsia & $68 \%$ \\
$\quad$ Intrapartum eclampsia & $16 \%$ \\
$\quad$ Postpartum eclampsia & $16 \%$ \\
Duration of pregnancy & \\
$\quad<34$ wks & $14 \%$ \\
$\quad 34-37$ weeks & $40 \%$ \\
$\quad>37$ wks & $16 \%$ \\
Income (yearly)35000Taka & $90 \%$ \\
Living condition (Slam dweller) & $90 \%$ \\
Occupation (Day Labor \& rick show puller) & $90 \%$ \\
\hline
\end{tabular}

At the time of admission all patients had tachycardia, tachyponea, adequate urine output $(100 \mathrm{ml} / 4$ hour $)$ and presence of knee jerk. Twenty percent of the women had severe SBP (more than $170 \mathrm{~m} \mathrm{mHg}$ ), twenty eight percent of the women had moderate SBP $(150-170 \mathrm{~m} \mathrm{~m} \mathrm{Hg})$ and thirty two percent of the women had normal SBP(less than $140 \mathrm{~m} \mathrm{~m} \mathrm{Hg}$ ). Twenty four percent of the women had severe DBP (DBP more than $110 \mathrm{~m} \mathrm{~m} \mathrm{Hg}$ ), fifty four percent women had moderate DBP (100-110 m m Hg) and twenty two percent of women had normal DBP(less than $100 \mathrm{~m} \mathrm{~m} \mathrm{Hg}$ ). Ten percent of women had no uinary albuminuria, twelve percent of women had one plus albuminuria, thirty eight percent of women had two plus albuminuria and forty percent of the women had three plus albuminuria.

Serum level in ecplampsia patients before giving $\mathrm{MgSO}_{4}$ is $0.47(0.15-1.04) \mathrm{m} \mathrm{m} \mathrm{mol} / \mathrm{L}$ and 24 hours after giving the loading dose of $\mathrm{MgSO}_{4}$ is $0.74(0.20$ 2.0) $\mathrm{m} \mathrm{mol} / \mathrm{L}$. After $\mathrm{MgSO}_{4}$ infusion, level raises. This change is significant $(\mathrm{P}<.001)$. The changes in serum electrolytes level before and 24 hours after magnesium sulfate therapy are not significant (Table II). Change in ionized magnesium level associated with change in diastolic blood pressure, systolic blood pressure, mean arterial pressure and albuminuria. This changes are also significant $(\mathrm{p}<.001)$ (Table III).

Table-II

Serum electrolytes in eclamptic patient

\begin{tabular}{lccc} 
Parameter & Before $(\mathrm{mmol} / \mathrm{L})$ & After $(\mathrm{mmol} / \mathrm{L})$ & $\mathrm{P}$ value \\
\hline $\mathrm{Mg}++$ & $0.47(0.15-1.04)$ & $0.74(0.20-2.0)$ & 0.001 \\
$\mathrm{Na}+$ & $143(132-158)$ & $141(124-150)$ & 0.320 \\
$\mathrm{~K}+$ & $3.7(1.7-8.3)$ & $3.5(1.9-8.2)$ & 0.062 \\
$\mathrm{Ca}++$ & $0.75(0.38-1.23)$ & $0.73(0.29-1.33)$ & 0.948
\end{tabular}

In this study only four percent patients had previous history of pregnancy induced hypertension and eclampsia, fifty two percent of the patients had sudden onset of eclamptic convulsion, whereas thirty eight percent of the patients had premonitory symptoms and ten percent of the patients had pregnancy induced hypertension which progress to eclampsia. 
Table-III

\begin{tabular}{lccc}
\multicolumn{3}{c}{ Change in Blood pressure and albuminuria in eclampsia patient } \\
Parameter & Before & After & P value \\
\hline Diastolic BP (mm Hg) & $108(70-130)$ & $90(70-120)$ & 0.001 \\
Systolic BP(mm Hg) & $160(110-220)$ & $137(120-190)$ & 0.001 \\
Mean Arterial Pressure (mm Hg) & $123(83-150)$ & $106(86-140)$ & 0.001 \\
Albuminuria (g/L) & $2+(0-3)$ & $1+(0-3$ & 0.001 \\
\hline
\end{tabular}

Results are expressed as median (range). Unpaired t-test was done as a test of significance.

\section{Discussion:}

Availability and accessibility to antenatal care plays an important role in the prevention of eclampsia. There is evidence that, $90 \%$ eclampsia seen in poor, under privileged, malnourished, illiterate younger primi 3, 17-19 who lived in urban slam or remote $\operatorname{areas}^{21}$ devoid of health care facility.

Magnesium sulphate is an ideal anticonvulsant drug because it has rapid onset of action and it control convulsion effectively $6,18,19$.Though there are some risks of magnesium toxicity during treatment with $\mathrm{MgSO}_{4}$, these can be overcome by close observation of the patient, and monitoring of some parameters and use of specific antidote injection calcium gluconate. Fortunately nobody developed such toxicity in this study.

In this study, serum ionized magnesium level in eclamptic patient before and after treatment with $\mathrm{MgSO}_{4}$ are $0.47(+0.18) \mathrm{m} \mathrm{mol} / \mathrm{L}$ and $0.74(+0.38 \mathrm{~m}$ $\mathrm{mol} / \mathrm{L})$, respectively. Abnormally low concentration of is found in the serum of the eclampsia patients and it is the possible independent determinant factor for developing eclampsia 4,10-13 in Bangladeshi women. As in the pathogenesis of eclampsia, ionized magnesium level is abnormally lowered, so the possible mechanisms of magnesium deficiency are:

Lack of ante partum care: Regarding ante partum care, seventy nine percent of women have no ( $39.6 \%$ ) or irregular(39\% of women have1-2 visits) antenatal care visit . This finding compatible with national statistics and other study 17,18,28. Ante partum care identifies risk factors and complication and rectifies it. In our counrty, only $20 \%$ women received regular ANC and 40\% have no ANC. Lack of dietary support \& discriminatory food allocation 3,21- 23 causes malnutririon. Bangladeshi people are mainly rice eater. Protein and green leafy vegetable comprises only $6 \%$ and $3 \%$ of their diet respectively 23. There was a strong association between primi gravida, low maternal age, low quality of life, illiteracy, poor ANC and eclampsia $3,23-26$. There is a close relationship between protein intake and magnesium balance and malnutrition .Mother's nutrition begin from her intrauterine life. Malnutrition particularly chronic energy deficiency and anaemia, contribute to poor maternal health and adverse pregnancy outcome for both mother and her infant .Forty percent of the adolescent girls, forty six percent of the non pregnant and thirty nine percent of the pregnant women are anaemic. Ninety seven percent of the women are house wife. Thirty four percent of the women belong to 19-24 years age group and $27.7 \%$ women of 25-29 years age group having malnutrition. Ninety five percent house hold headed by male person and sixty percent house hold head never attend school $^{26}$. Nausea, protracted vomiting during pregnancy, 6 Increased phosphorylation after 28 weeks of gestation both in mother and fetal cell ${ }^{6}$, all together causes magnesium deficiency. That is why seventy percent eclampsia seen in antepartum period. ${ }^{7}$

Mismanaged labor: In prolonged labor, patients have neither food nor fluid, or hyper alimentation with magnesium or mineral free fluid ${ }^{27}$. Lack of nutritional support ${ }^{4}$, increased metabolic and endocrine activity of stressful situation depletes body $^{\text {'s }}$ magnesium stores ${ }^{6}$ during labor. Anxiety, fear, and other emotional reaction may affect the rate and depth of respiration and consequently the $\mathrm{CO}_{2}$ content of blood \& acid-base balance ${ }^{6}$. These imbalance causes tissue irritability and convulsion 4, 10-13 in the absence of hypertension and albuminuria. Eighty five percent deliveries occur at home. Eighty 
two percent of delivery is unattended or attended by unskilled person. Only 18\%delivery attended by medically trained person. ${ }^{28}$ Complication are more among attended labor and delivery. Findings of this study compatible with other studies. ${ }^{18,19}$

Mismanaged puerperium: Puerperium is a hypercatabolic condition. Lack of dietary support and fluid imbalance put the mother on risk of eclampsia .Only 21 percent women received postnatal care. 14.5 percent developed postpartum complication 28 .Extrinsic factors such as - Inadequate perinatal care, ${ }^{28}$ illiteracy (47\% women never attend school) and poor socio-economic condition ${ }^{26}$ which affect outcome of pregnancy. Findings of the study have similarity with national statistics and other studies 18,19 .

Low maternal age: Women at or below 20years, because of growth spurt and increased metabolic activity increases magnesium demand ${ }^{6}$, In Bangladesh early marriage are common. Seventy two percent of 15-19 years girls are married and they contribute approximately $20 \%$ of total pregnancy ${ }^{29}$. They are physically and psychologically immature for reproduction. Forty six percent of the children under five years are under weight and $36.2 \%$ are stunted 28 Teen age $(69.4 \%$ women became married before the age of 18 years $)^{26}$ pregnant women unable to bear the stress of pregnancy and labor. So pregnancy outcome among teen age mother are complicated .This findings are compatible with other studies $\mathbf{1 7 , 1 8}$

In this study, eclamptic patient after receiving in hospital infused Hartsol solution and loading dose of $\mathrm{MgSO}_{4}$. After stabilization, there was induction of labor with misoprostol tab, oxytocin drip or LSCS operation according to indication. Patients with high systolic BP $>180 \mathrm{~mm} \mathrm{Hg}$ or Diastolic BP $>110 \mathrm{~mm}$ $\mathrm{Hg}$, treated by giving $1 / \mathrm{V}$ inj. Hydralazine. In preterm patient injection Oradexon $2 \frac{1}{2}$ ampule $1 / \mathrm{m}$ for fetal lung maturity or injection Oradexon 1-2 ampule $1 / \mathrm{v}$ in suspected cases of cerebral edema were given. Despite of these treatment serum electrolytes level before and after $\mathrm{MgSO}_{4}$ infusion remain more or less same except significant change inlevel.

Dr. Monira Ahmed ${ }^{18}$ Anwary S A ${ }^{19}$ in their study showed that there is reduction in serum magnesium concentration in eclampsia patient before treatment with magnesium sulfate and level rises after therapy. They suggested that this lower level was partly due to hemodilution and partly due to hyper metabolic condition of pregnancy. But eclamptic patient had less intravascular volume ${ }^{14,17}$ or they are volume depleted.

Hypertensive disorders of pregnancy, which account for approximately $15 \%$ of pregnancy related deaths 30 , represent the 3 rd leading cause of maternal morbidity and mortality in USA and in Bangladesh. The cause of eclampsia still remains elusive, but continued research provided hope with regard to screening, improved diagnosis and management. Treatment and management of the hypertensive disorder of pregnancy have not changed substantially in the past 50 years ${ }^{30,31}$.

Eclampsia occur suddenly 15, 16, 31 . Worldwide interest is going in the prevention for eclampsia as a part of antenatal care or treatment strategies. Serum Electrolytes measurement is expensive, not easily available. So dietary correction, prepregnancy counselling, antenatal care and postnatal care can prevent the development of eclampsia ${ }^{28}$.

The role of $\mathrm{MgSO}_{4}$ in the treatment of eclampsia is clear because after administration of $\mathrm{MgSO}_{4}$ pulse, Blood pressure, proteinuria, level of consciousness improved and no further convulsion occur. Role of in causation of eclampsia is not known but low level of is found in eclampsia patient compared to the same patients 24 hours after giving the loading dose of $\mathrm{MgSO}_{4}$. This study showing that the factors most predictive of eclampsia in pregnant women is possibly abnormal low concentration of in serum. On the basis of these findings predisposing factors, aetiopathogenesis and sign symptoms are also correlated. ${ }^{16,18,19}$

\section{Conclusion:}

The present study shows that eclampsia is a malnutrition- poverty related disease and the association of low level of ionized magnesium with the occurrence of eclamptic fit. So, it is presumptive that abnormally low concentration of ionized magnesium in the serum is responsible for eclamptic convulsion.

\section{Acknowledgement:}

I am very grateful to the women participated in this study, doctors, the nursing and laboratory stuff of Dhaka Medical College Hospital for their help and kind 
cooperation .My heartfelt thanks to Professor Liaquat Ali, Mrs. Farzana Parvin Nipa, Biomedical Research Group, BIRDEM who help me directly in performing this work and statistical analysis of this study.

\section{References:}

1. Prof. S Chowdhury: Maternal Malnutrition-----an underlying factor of maternal and neonatal death: ICMH NC 1 1st National conference on "Achieving Millennium Development Goals 4 and 5, 30TH-31ST March, 2007; p15

2. N. Sultana, A. Begum, K. Begum, .A comparative study of loading dose of magnesium sulphate versus intra muscular injection of magnesium sulphate in eclamptic patient $-\mathrm{J}$. Bangladesh College of Phys Surg 2003; 21: 63-68.

3. Aynon Nahar Begum, Studies on Nutritional status of preeclampsia and eclampsia in selected population of Bangladesh (Thesis), Institute of Nutrition and Food Science, University of Dhaka, 1995;p77,93,120-124.

4. Joel B. Mason / Irwin H. Rosenberg., Protein Energy Malnutrition; Harrison Principle of Medicine ; McGrawHill, New York, Chapter- 72, 13th edition 1994, vol -1, p440-446.

5. The Mineral that could Have Saved 4 Million Women by Bill Sardi is President of Knowledge of Health, Inc., San Dimas, California. His Latest Book is in Search of the World's Best Water, 2002.LewRockwell.com Home Page

6. William C. Mabie \& Baha M. Sibai: Hypertensive states of pregnancy; pathophysiology :Current obstetric Gynaecologic Diagnosis and treatment, 8th edition, Appleton \& Lange, 1994; 381-5.

7. D.C.Dutta ; Physiological change during pregnancy: Text book of obstetrics , 6th edition 2005, New Central book Agency(p)Lt, KolKata,p51,56

8. M. Rashid, Shahadat Hossain ,Mahbub Ara T A Chowdhury, Suhrab Ali: Toxaemia of Pregnancy is not a Hypernatraemic condition-A Study of 100 cases. Bangladesh Journal of Obstetric and Gynaecology; 1996; vol 11(2):90-94

9. Michael F. Holick, Stephen M Krane: Disorder of magnesium metabolism: Harrison Principle of Medicine, McGraw-Hill, New York, 15th edition, 2001, vol 2 p2198;

10. Alan Gowenlock, Varleys practical clinical Biochemistry: Nurtition: Normal and Clinical 6th edition, CBS publishers \& Distributors, India, 1988, chapter 21: 715

11. Corinne H. Rabinson, Marilyn R Lowler, Normal and Therapeutic nutrition 15th edi.,Macmillan Company, New York1986,p110-111

12. Maurice E. Shils, James A. olson, Moshe Shike 'Magnesium', Modern nutrition 8th edition. Lippincott\& Wilkins, 1994, Vol 1: p 164

13. West, Toss, Mason, Van Bruggen, Davis GK: The Metabolism of inorganic elements: The text Book of Biochemistry: 4th edition, 1974. : Oxford \& IBH publishing Co. ptv Ltd. Calcutta, p1386
14. Bartons Levine, MD. Jack W. Coburn, M S: "Magnesium, The Mimic/Antagonist of calcium" New England Journal of Medicine; 1984: Vol 310; No. 19, 1253-54.

15. Keith, Edmonds: Hypertension and renal disease in pg: Dewhurst's Textbook of Obstetric and Gynaecology for post graduates; 6th edi: 2000 Blackwell Science, p166.

16. Aashit K Shah, MD, Associate Professor, Dept. of Neurology, Detroit Medical Centre, Wayne state University, Preeclampsia and eclampsia. Medicine info<info@ho.dhlgroup.com>

17. Luan Ji-quin: The Treatment of Eclampsia by early interruption of pregnancy; a 15 years review. Asia Oceania J. obstet, gynaecol, 1989, vol 15, no1; 33-35

18. Dr. Monira Ahmed, Estimation of serum Magnesium level in eclamptic woman and fetal cord blood before and after giving magnesium sulfate; Dissertation(no3038) (2002.), BCPS Library.p90-100

19. Anwary SA, Serum Magnesium levels in Eclaptie patient (Dissertation) Dhaka Bangabandhu Sheikh Mujib Medical University 2000; Dhaka, BCPS Library ;p54-55

20. Dr.Touhida Ahsan ;Serum zinc level in pre eclampsia , Dissertation ,2001 January; BCPS Library;p3-4

21. The Fifth Five Year Plan 1997-2002; 22.2.10 pageXX114Planning Commission, Ministry of Planning,Bangladesh

22. Kale K.M., Aswar N. R. Jogdand G.S., Bila Walkar J.S. Socio-medical co-relates of teenage pregnacy. The Journal of Obs and Gy of India; April 1996; Vol 46: 2.

23. Nutrition Survey in Bangladesh: 4 studies. Library: Food and Nutrition Dept. of Dhaka University, 1962-64, 1975-76, 1981-82, 1995-96.

24. K. Park; Park's text book of Preventive and Social Medicine, 16th edition 2000, Banarsidasbhanot, page 416,440

25. L. Dilip R de Silva and T.M. Sunethra Arekorala: Micro nutrient status of plantation workers in Srilanka during pregancy and post partum. J Obstet and Gynaecol Res; 1996. Vol: 22, no-3: 239-246

26. Child and Mother Nutrition Survey of Bangladesh 2005, ppxix, 53, 54

27. Daniel Rudmen, Julia C.Bleier; Protein and Energy under nutrition: Harrison Principle of Medicine: Chapter 789, edition 10th ,vol-1,p 439

28. Bangladesh Demographic and household survey 2007 (preliminary report) p19-23

29. Bangladesh Demographic and household survey 1993-94 and 1996-97

30. E. medicine Pregnancy Eclampsia: Article by Micheal B. Brooks, MD ; consulting stuff Dept. of Emergency medicine Pub Med. Bethesda North Medical Centre, 2001

31. Douglas K. A Redman C.W.G Eclampsia in the United Kingdom.Br Med J, 1994, p309 